\title{
Customized Yeast to Start the Season - A Successful Experience for the Stability of Alcoholic Fermentation?
}

\author{
Claudia Steckelberg, Silvio R. Andrietta, Maria G.S. Andrietta
}

\begin{abstract}
Select yeasts have been widely adopted by Brazilian distilleries to start their fermentation processes. These yeasts are isolated from industrial processes, including mainly the ones belonging to the genus Saccharomycessensustricto. These yeasts are introduced into the process by the feedstock and are capable of partially or fully eliminating the yeast used as inoculum, mainly when the yeasts used are for baking purposes. The ease with which these yeasts remain in the process in expressive amounts is associated with their ability to withstand the unique process conditions (high alcoholic content, low pH, among others). This yeast is then isolated from the process in the industrial unit and propagated in large amounts to be sold to other plants that use it to start their seasons. Another emerging alternative is when each unit isolates the yeast from its own process and propagates it to start its own fermentation. This work followed the dynamics of the yeast population of an industrial plant during three seasons using as inoculum a yeast strain isolated from their own process (customized yeast). The results suggest that the customized yeast (SM584) was able to remain throughout the seasons for the three years assessed, even if at some point it was not the dominant yeast. It is also possible to note that even when using customized yeast, the yeast population dynamics in fermentation tanks is different from one season to another.
\end{abstract}

Index Terms-Alcoholic fermentation, bioethanol, Saccharomyces sensustricto, Yeast.

\section{I - INTRODUCTION}

Ethanol production and use in Brazil are presently the best examples of introduction of energy in large-scale production [1]. The National Alcohol Program (Proálcool) created in the 1970 s by the military government was conceived to allow Brazil to produce an alternative fuel to oil, since the price of this fuel rose from US\$ 3.26/barrel in 1973 to US\$ 12.40 /barrel in 1975 [2].

Before 1975, ethanol was produced in Brazil only from molasses, a byproduct of sugar production. With the implementation of Proálcool, sugarcane juice became the main component of the material to be transformed into ethanol. At that time new units processing sugarcane to obtain ethanol appeared (autonomous distilleries). The mills producing ethanol only as a sugar production byproduct, started to prioritize ethanol production as a result of the government incentives.

Claudia Steckelberg, CPQBA, Universidade de Campinas, São Paulo, Brasil.

Silvio R. Andrietta, Biocontal, Engenharia de Bioprocessos, São Paulo, Brasil

Maria da Graça S. Andrietta, CPQBA, Universidade de Campinas, São Paulo, Brasil
With the end of the military regime and the beginning of the New Republic, Proálcool ceased to exist as a government program to promote the production of fuel alcohol, but public policies supporting sugarcane production and alcohol use remained [3].

Forty years after the introduction of Proálcool, the units processing sugarcane structured their production based on the global market trend. When sugar prices are on the rise in the international market, the units start producing larger amounts of this product. When ethanol prices become more attractive, the units turn to the production of this fuel. The 2018 season, for example, according to UNICA (the Sugarcane Industry Union) [4] was "an ethanol-based" season.

The fermentation processes installed in Brazil are mostly designed to use cell recycling [5]. At the beginning of the season, the units start their fermentation with large volumes of Saccharomycessensustrictoyeast cells. This group gathers yeasts belonging to the Saccharomyces genus, which are relevant for the industry and for the basic science as well [6]. Yeasts usually used as start-up can be baker's or select ones. Baker's yeast are those developed for bread fermentation purposes and used to start up fermentation because they are easy to obtain and have low cost. Select yeasts are isolated from alcohol fermentation industrial processes [7], and propagated in large scale and sold as inoculum to start up industrial fermentations. Before the introduction of karyotyping analysis [8], it was believed that the yeast introduced to start a season as inoculum was the same one that ended the season. Studies carried out by Basso and colleagues [9] found that yeasts that started the season were no longer present in the fermentation tanks at the end of the season. Based on this finding, research was designed to select yeasts from the industrial units with the ideal characteristics for the fermentation tank environment and that could be used by all other units. From the outset, the work was developed to select strains that could be used by ethanol producing units [10], [11], [12]. Presently, the mills acquire some select strains sold in large scale to start their season, with the main strains being PE, CAT, SA, FT858.

The practice of using select strains to start the season has proven to be a safe procedure, since the process begins with a strain isolated from a process similar to the process that is about to begin. However, recent work has shown that even when select yeast strains are used, they may be replaced by other strains that are native of the process [7], [13]. An alternative found by the industries is to isolate the native strains from the process where they installed to start the following season. In order to evaluate the success of this strategy, this work aimed to assess the dominance and permanence of a strain used as inoculum and isolated from the process for a period of three seasons. 


\section{MATERIAL AND METHODS}

\section{A. Samples}

The samples were collected from an ethanol production process from sugarcane and byproducts in a unit operating continuously with cell recycling in the State of São Paulo, Brazil. The unit used the Saccharomyces sensustrictostrain as inoculum for the three seasons assessed, and this strain was isolated at this same unit from the previous season. For the purposes of presentation in this work, this strain will be referred to as SM584. Samples were collected at nonregular intervals, not longer than 40 days during the 2015, 2016 and 2017 seasons. The samples were previously diluted in $0.9 \%$ saline solution and cultivated in WLN differential medium (DIFCO \# 424) supplemented with 100 ppm of monensin for inhibition of bacteria found in the samples. The surface-spreading technique was used. Plates were incubated at $32^{\circ} \mathrm{C}$ for seven days for selection of different colony morphologies. The distinction of biotypes was made based on the morphological differentiation of the colony. The parameters used were size, color and texture. Different biotypes were, in duplicate, purified and maintained in PDA slant (Potato dextrose agar).

\section{B. Yeast Identification}

Yeasts were identified molecularly through the karyotyping technique.Chromosome isolation was made by modifying a protocol proposed by Blond and Vezinhét [11]. Chromosomes were spread using agarose gel in pulsed-field electrophoresis in CHEF III (Bio-Rad) equipment.The gel was colored with ethidium bromide prepared in a TAFE solution $(0.5 \mathrm{l} / \mathrm{ml})$ and analyzed under ultraviolet light (UVP BioImagem System).The chromosomal profile, made in duplicate for one of the different biotypes (colony morphology).

\section{RESULTS AND DISCUSSIONS}

Figures 1, 2 and 3 present the results in terms of yeast dynamics in the 2015, 2016 and 2017 seasons respectively.

The 2015 season started in May and ended in December. Figure 1 presents the yeast population dynamics for this season. Yeast population in the tanks was always higher than $2.5 \times 10^{8}$ yeast cells per $\mathrm{ml}$ of must, which is the count expected in the fermentation tanks (Table 1).

Until the month of June (75 days into the season) the SM 584 strain remained as the only yeast strain in the tanks with sensitive counts to the method used, that is, counts from $10^{7}$. The native yeasts started to cohabit the tanks with a sensitive count to the method used from the 97th day of the season.

Table 1: Total yeast cell population (CFU/ml) during the 2015 season

\begin{tabular}{|c|c|c|c|c|c|c|}
\hline Season days & $\begin{array}{c}\underline{\mathbf{2 6}} \\
3.0 \times 10^{8}\end{array}$ & $\begin{array}{c}\underline{\mathbf{5 8}} \\
3.5 \times 10^{9}\end{array}$ & $\begin{array}{c}\underline{\mathbf{7 5}} \\
1.0 \times 10^{9}\end{array}$ & $\begin{array}{c}\underline{97} \\
7.3 \times 10^{8}\end{array}$ & $\begin{array}{c}\underline{\mathbf{1 1 6}} \\
4.2 \times 10^{8}\end{array}$ & $\begin{array}{c}\underline{\mathbf{1 6 0}} \\
3.5 \times 10^{8}\end{array}$ \\
\hline Season days & 167 & $\underline{188}$ & $\underline{215}$ & $\underline{237}$ & \multicolumn{2}{|c|}{$\underline{\mathbf{2 5 5}}$} \\
\hline Population ( CUF) & $3.9 \times 10^{9}$ & $2.7 \times 10^{8}$ & $6.5 \times 10^{9}$ & $2.0 \times 10^{9}$ & \multicolumn{2}{|c|}{$9.0 \times 10^{8}$} \\
\hline
\end{tabular}

Over the season it is possible to note the presence of 11 native yeasts that, at some point during the season, were present in the process. Only ninety-seven days into the season (July), it is possible to identity the presence of a native yeast (L1/15), representing only $4.2 \%$ of the population. In August, L115 is no longer detected, but three different native yeasts are installed in the process (L2, L3, and L4) without, however, being able to dominate the process, since they together represent $28.6 \%$ of the yeast population found in the tank. SM 584 is still the dominant strain, representing $71.4 \%$ of the population. In September (160 days into the season), SM 584 becomes the minority $(25.7 \%)$ compared with the yeast population in the tank, since the other two native yeast strains installed (L5/15 and L6/16), together representing $74.3 \%$ of the total population. Yeasts L5/15 and L6/15 represent $45.7 \%$ and $28.6 \%$ of the population, respectively. Another collection in September (167 days) shows that SM 584 resumed its dominance, and now represents $76 \%$ of the population. SM 584 is capable of eliminating L6/15, but not fully L5/15, which represents $15 \%$ of the population in this collection. It is also possible to note the presence of these two new native yeast strains (L7 and L8), which together with L5/15, represent $24 \%$ of the population. In the month of October (188 days), SM 584 population undergoes a new drop, representing $18.5 \%$ of the population. The dominance is taken over by a new native strain (L9/15), which aggressively represents $70.4 \%$ of the yeast population. It is also possible to identity the presence of a native yeast L10/15, representing only $11.1 \%$ of the population. In November (215 days into the season), SM 584 is capable of representing $50 \%$ of the yeast population found in the tank, cohabiting with two other native yeast strains, L7/15, which had already been detected in the month of September as inhabiting the tank. In December, at the closing of the season, two collections were made and we note that SM 584 regained its dominance. It kept, as in November (215 days into the season), representing $50 \%$ of the population in the first collection of the month (237 days into the season), dividing the tank space with the L9/15 native strain, representing $50 \%$ of the population. In the second collection ( 255 days into the season), at the closing of the season, it represents $77.8 \%$ of the yeast population in the tanks, cohabiting the tanks with native yeast L11/15, which was the dominant strain in the month of November. 


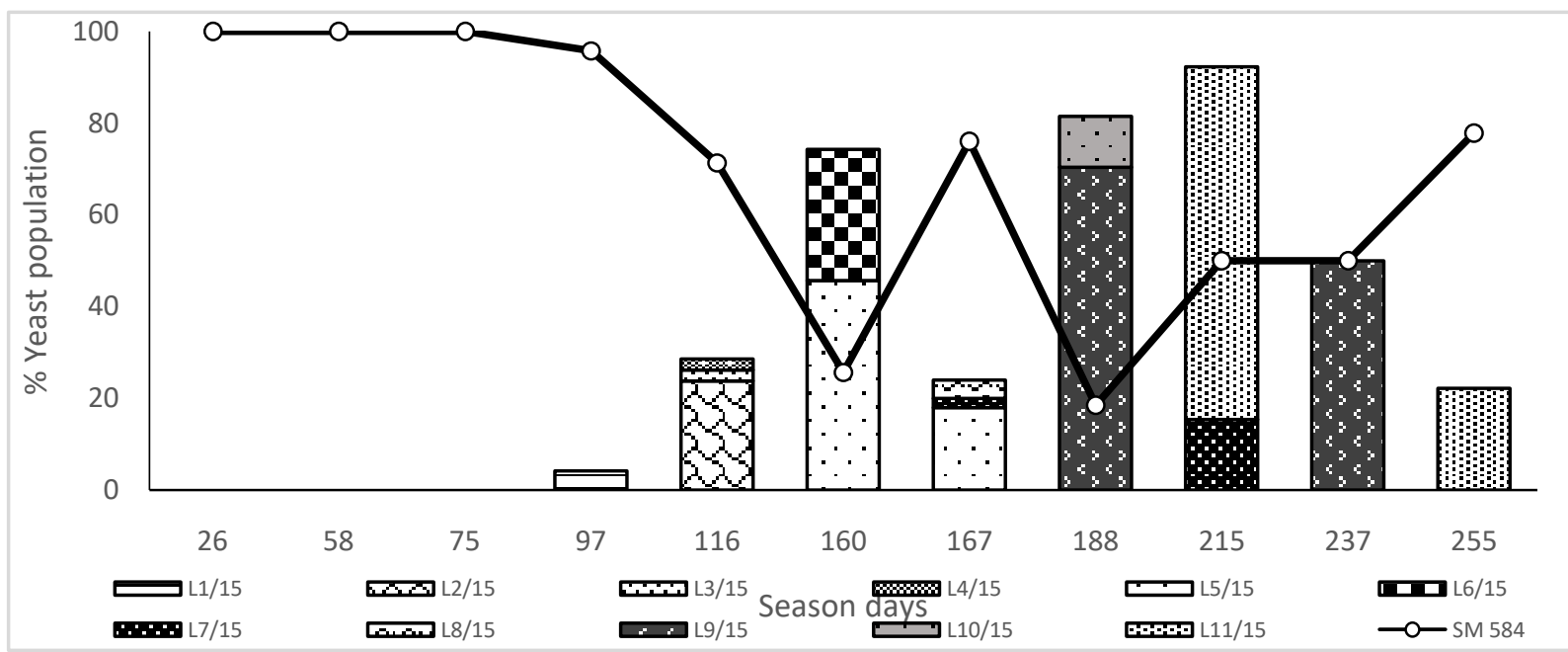

Figure 1: Yeast dynamics in the fermentation process during the 2015 season

The 2016 season started in May and ended in December. Figure 2 presents the yeast population dynamics for this season. Yeast population in the tanks was always higher than $1.5 \times 10^{8}$ yeast cells per ml of must, which is the count expected in the fermentation tanks (Table 2).

Table 2: Total yeast cell population $(\mathrm{CFU} / \mathrm{ml})$ during the 2016 season

\begin{tabular}{|lc|c|c|c|c|c|}
\hline & Season days & $\underline{\mathbf{2 3}}$ & $\underline{\mathbf{5 2}}$ & $\underline{\mathbf{7 9}}$ & $\underline{\mathbf{9 9}}$ & $\underline{\mathbf{1 2 9}}$ \\
Population ( CUF) & & $2.0 \times 10^{9}$ & $1.1 \times 10^{9}$ & $1.5 \times 10^{8}$ & $3.0 \times 10^{8}$ & $1.2 \times 10^{9}$ \\
\hline & Season days & $\underline{\mathbf{1 4 9}}$ & $\underline{\mathbf{1 7 0}}$ & $\underline{\mathbf{1 9 1}}$ & $\underline{\mathbf{2 0 0}}$ & $\underline{\mathbf{2 3 2}}$ \\
Population ( CUF) & $1.6 \times 10^{9}$ & $5.8 \times 10^{8}$ & $1.2 \times 10^{9}$ & $3.3 \times 10^{9}$ & $8.0 \times 10^{8}$ \\
\hline
\end{tabular}

200 days into the season (still in September), it is possible to

Until the month of June (99 days into the season) the SM 584 strain remained as the only yeast strain in the tanks with sensitive counts to the method used, that is, counts from $10^{7}$. The native yeasts started to cohabit the tanks with a sensitive count to the method used from the 129th day of the season. During the season, it is possible to note the presence of 10 native yeasts that, at some point during the season, where present in the process. At ninety-nine days into the season (June), it is possible to identify the presence of a native yeast $(\mathrm{L} 1 / 16)$, representing only $25 \%$ of the population. It remains in the process until July ( 99 days into the season), but it is not capable of increasing its population, which at this point represents $12.6 \%$ of the yeast population in the tanks. Even though we detected the presence of second native yeast (L2/16), it represents only $6.3 \%$ of the yeast population, with SM 584 still the dominant yeast, representing $81.1 \%$ of the strains inhabiting the tanks. At 170 days into the season (August), yeasts L1/16 and L2/16 are still undetected in the tanks, and it is possible to note that even though SM 584 is still the dominant strain (56.1\%), it starts to cohabit with another native strain in the tank (L3/16), which represents $43.9 \%$ of the population. In September (191 days into the season), SM 584 is capable of eliminating native yeast L3/16, which ceases to be the strain in highest concentration and starts to share its population with three other native strains (L4/16, L5/16 and L6/16), and L5 starts to dominate the tank, representing $50 \%$ of the population. Strains L4/16 and L6/16 represent $8.3 \%$ of the population each, with SM 584 representing only $33.4 \%$ of the population. These three strains (L4/16, L5/16 and L6/16) are quickly eliminated, but the SM 584 strains is still unable to become dominant in terms of population in the tank. At note the presence of three other yeast strains, L7/16, L8/16 and L9/1, with L8 capable of representing $60.7 \%$ of the population, and with SM 584 representing $30.3 \%$ of the population. L7 and L9 represent 3 and $6 \%$ of the population, respectively. At the end of the season, in November (232 days into the season), SM 584 becomes dominant again, representing $75 \%$ of the population, sharing tank space with a strain detected for the first time (L10/16), similarly to native yeast $\mathrm{L} 5 / 16$, which had been detected at a previous collection, then representing the dominant yeast (50\% at 170 days into the season). At this moment, native yeast L5/16 represents, similarly to native yeast L10/16, only $12.5 \%$ of the population.

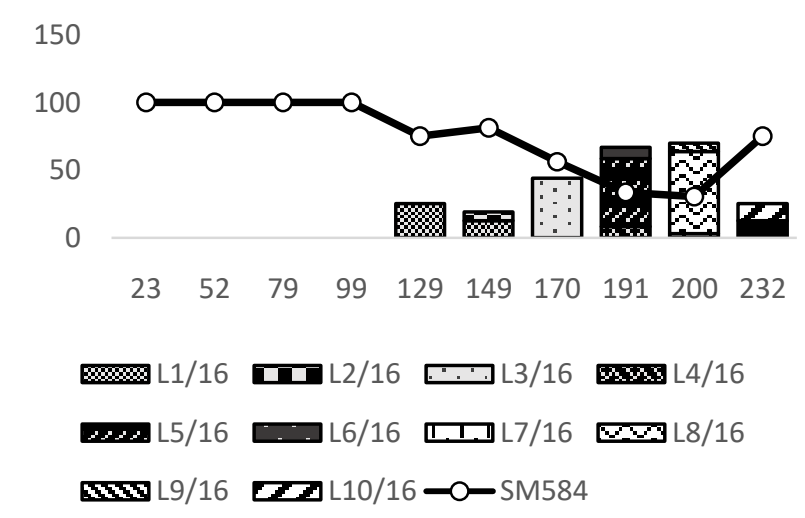

Figure 2: Yeast dynamics in the fermentation process during the 2016 season 
The 2017 season started in May and ended in December. Figure 3 presents the yeast population dynamics for this season. Yeast population in the tanks was always higher than $2.5 \times 10^{8}$ yeast cells per ml of must, which is the count expected in the fermentation tanks (Table 3 ).

Table 3: Total yeast cell population (CFU/ml) during the 2017 season

\begin{tabular}{|cc|c|c|c|c|c|c|}
\hline & Season days & $\underline{\mathbf{4 1}}$ & $\underline{\mathbf{6 4}}$ & $\underline{\mathbf{8 5}}$ & $\underline{\mathbf{1 0 6}}$ & $\underline{\mathbf{1 3 4}}$ & $\underline{\mathbf{1 5 3}}$ \\
Population ( CUF) & Season days & $\underline{\mathbf{1 6 4}}$ & $\underline{\mathbf{1 7 6}}$ & $\underline{\mathbf{1 8 8}}$ & $\underline{\mathbf{2 1 2}}$ & \multicolumn{2}{c|}{$\underline{\underline{\mathbf{2 3 1}}}$} \\
\hline & $2.9 \times 10^{8}$ & $1.9 \times 10^{9}$ & $6.3 \times 10^{8}$ & $4.3 \times 10^{8}$ & $1.1 \times 10^{9}$ & $5.0 \times 10^{9}$ \\
\hline
\end{tabular}

season, still in October, when SM 584, even as dominant yeast $(63.5 \%)$ is no longer the only strain present in the

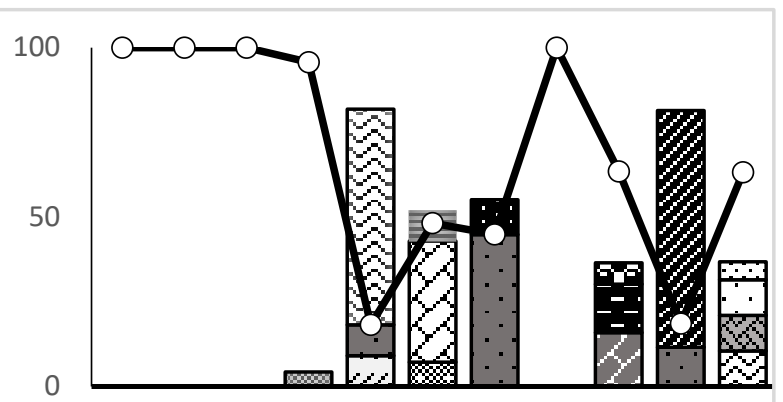

$\begin{array}{lllllllllll}41 & 64 & 85 & 106 & 134 & 153 & 164 & 176 & 188 & 212 & 231\end{array}$

\begin{tabular}{|c|c|c|}
\hline$\infty$ & L1/17 & L2/17 \\
\hline L4/17 & $\mathrm{L} / \mathrm{m} / \mathrm{x}$ & एवL6/17 \\
\hline$\therefore$ L8/17 & $\therefore$ L9/17 & [F|10/17 \\
\hline
\end{tabular}

Figure 3: Yeast dynamics in the fermentation process during the 2017 season

Until the month of June (85 days into the season) the SM 584 strain remained as the only yeast strain in the tanks with sensitive counts to the method used, that is, counts from $10^{7} / \mathrm{ml}$. The native yeasts started to cohabit the tanks with a sensitive count to the method used at 106 days into the season. During the season, it is possible to note the presence of 15 native yeasts that, at some point during the season, where present in the process. At one hundred six days into the season (June), it is possible to identity the presence of a native yeast (L1/17), representing only $4.3 \%$ of the population. It is quickly eliminated from the process. At 134 days into the season (August), L1/17 is no longer found in the tanks, and SM 584 is no longer the dominant strain, but shares the tanks with three other native strains, one of which, L4/17, is the dominant, representing $63.3 \%$ of the total yeast population in the tanks. The other two (L2/17 and L3/17) each represent $9.1 \%$ of the total yeast population present. At this moment, SM 584 participates with only $18.2 \%$ of total yeasts inhabiting the process. At 153 days into the season (December), yeast composition in the tanks is completely changed, SM 584 becomes dominant, representing $48.2 \%$ of the populating and sharing the tank with three other native strains: L5/17, L6/17 and L7/17, representing $7.2 \%, 35.7 \%$ and $8.9 \%$ of the total population, respectively. Still in September (164 days into the season), SM 584 represents $44.9 \%$ of the population, and native yeast $\mathrm{L} 3 / 17$ is once again found at the same concentration of SM $584(44.9 \%)$. At this time, native yeast L8/17 emerges, with $10.3 \%$ participation in the tanks. At 176 days into the season (October), SM584 represents $100 \%$ of the yeast population in the tanks. This situation changes at 188 days into the tanks, since it cohabits with strain FT 858, which was purposefully introduced in the process, and with two other different native strains, L9/17 (14.3\%) and L10/17 (6.3\%). In November (212 days into the season), SM 584 loses dominance again in the tanks, representing only $18.6 \%$ of the yeast population, the other share $(81.4 \%)$ shared with a strain that appeared for the first time in the process (L11/17), which dominates and represents $69.8 \%$ of the total yeast population, and L3/17, which had been previously present (134 and 164 days into the season), representing now only $11.6 \%$ of the total population in the tanks. The season ends at 231 days in the month of December. At this point, SM 584 yeast started to represent $63.2 \%$ of the yeast population. The other portion of the population is represented by four new yeast strains, which emerge for the first time in the season. They are L12/17; L13/17; L14/17 and $\mathrm{L} 15 / 17$, which represent, with regard to the population in the process, $10.5 \% ; 10.5 \% ; 10.5 \%$ and $5.3 \%$, respectively.

\section{DISCUSSION}

Yeast behavior dynamics in the tanks was similar in the three seasons studied, in spite of some specific particularities for each year assessed. Yeast SM 584, which was isolated from the process in the previous season and used as inoculum at the start of the activities at the unit, even though it was not dominant during the crushing period, was able to persist in the process until the end of the industrial operation. Until near 90 days into the season, it was the only strain in the fermentation tanks. From this point, it is possible to note the presence of other yeast strains, known as native, since they originate from the process itself. In all seasons, there was a moment when SM 584 was the lowest concentration strain. This moment took place between 160 and 215 days into the 2015 season, between 191 and 200 into the 2016 season and between 134 and 212 into the 2016 season. In the 2015 and 2017 seasons, the dominance of SM 584 oscillated over the months, that is, at a certain point it lost dominance, resumed it and lost it again, differently from the 2016 season, when SM 584 started losing dominance and ended up representing $30 \%$ of the population, and from there it resumed leadership.

As for the native yeasts, there were few capable of emerging in more than one period during the seasons. In the 2015 season, out of the eleven strains found, only four were identified in more than one period, L5/15, which was present at two collections (160 and 167 days) and L7 (at the collections at 167 and 215 days), and L9, at the collections at 188 and 237 days and L 11 (at 215 and 255 days). In the 2016 season, out of the ten strains inhabiting the tanks, only two were able to be identified in more than one collection. L1/16 was detected at collections at 129 and 149 days, and 
L5/16 at collections at 191 and 232 days. In the 2017 season, out of the fifteen native strains identified, only one was identified at more than one collection, which was L3/17, a native strain detected at three collections, at 134, 164 and 212 days. The intermittence of the period of emergence of some native strains during the season, as native L7/15 detected in collections at 167 and 215 days and undetected in collection at 188 days, must be associated to the insufficiency of the detection method. The strain was supposedly present at 188 days, but the methodology used was unable to detect its presence. A similar fact may have taken place with L9/15, L11/15 and L3/17 strains.

SM 584 was most dominant in the 2016 season, since the lowest concentration found for this strain was $30.3 \%$. In the 2015 and 2017 seasons, the SM 584 strain represented less than $20 \%$ of the yeast population in the tanks at a certain point.

In the 2017 season, the unit chose to "inject" the select yeast FT 858 in the fermentation tanks. This strategy was adopted by the oscillation presented by SM 584 in dominating the process. It was injected near the period of 188 days into the season, representing $15.9 \%$ of the yeast population in the tanks. At the following collection, that is 212 days into the season, FT 858 was no longer detected.

The data presented in this work lead to the conclusion that, even though the use of yeast isolated from the process (customized) is a recommended practice, since the select yeast (SM 584) was able to persist throughout the seasons, and be partially dominant at the three units assessed, it is important to highlight that each season presents a particular behavior profile, even when using the customized yeast.

The practice of using customized yeast strains as inoculum by the unit to start the season was more promising when compared with the use of select strains available in the market, such as PE, CAT, and FT. Differently from the results found in this work, findings by some researchers who studied permanence in the PE strain fermentation process [10] suggest that the PE strain was unable to remain at the end of the season at the industrial units that started their seasons using this yeast strain [7],[12].

\section{REFERENCES}

[1] I.C. Macedo. Situação atual e perspectivas do etanol. Estudos avançados 21, v.59, p.157-167, 2007

[2] P.M. Nastari. The role of surgacane in Brazil's history and economy.Ph.D. Dissertation, Iowa State University, Ames, 1983.

[3] L.A.B. Cortez, C.H.B. Cruz, G.M. Souza, H. Cantarella, M.A. Sluys, R. Maciel Filho. "Da criação ao fim do Proálcool", Próalcool Universidade e Empresas: 40 Anos de Ciência e Tecnologia para o Etanol Brasileiro, 29-60, 2016

[4] ÚNICA. Disponível http://www.unicadata.com.br/lista. Acessoem 20 de junho 2018.

[5] M.G.S. Andrietta, S.R. Andrietta, E.N.A. Stupiello E.N.A. Bioethanol - What Has Brazil Learned about Yeasts Inhabiting the Ethanol Production Processes from Sugar Cane? Biofuel Production-Recent Developments and Prospects. Ed: Bernardes, M.A.S., 596f.,Intech, Set. 2011.

[6] S. Rainieri, C. Zambonelli, Y. Kaneko. Review - Saccharomyces sensustricto: Systematics Genetic Diversity and Evolution. Journal of Bioscience and Bioengineering, v.96, n.1, p.1-9, 2003.

[7] C. Steckelberg, P.R. Kitaka, S.R. Andrietta, M.G.S. Andrietta. Dominance and Persistence of PE strains

(SaccharomycesSensuStricto) in Brazilian Bioethanol Fermentation Tanks (One Unit Four Seasons). International Journal of New Technology and Research (IJNTR), v.3, i.6, p.69-71, 2017

[8] L.C. Basso, A.J. Oliveira, A.A. Orelli, C.R. Campos, C.R. Gallo, H.V. Amorim. Dominância das leveduras contaminantes sobre as linhagens industriais avaliada pela técnica de cariotipagem. Anais Congresso Nacional da STAB, v.5, n.1, p.246-250, Piracicaba, 1993.

[9] E.A. da Silva-Filho, H.F. de Melo, D.F. Antunes, S.K. dos Santos, A do Monte Resende, D.A. Simões, M.A. Morais. Isolation by genetic and physiological characteristics of a fuel-ethanol fermentative Saccharomyces cerevisae strain with potential for genetic manipulation. Journal Industry Microbiology\&Biotechnology, v.32, i.10, p.481-486, 2005.

[10] L.C. Basso, H.V. Amorim, A.J. Oliveira, M.L. Lopes. Yeast selection for fuel ethanol production in Brazil. FEMS Yeast Research, v.8, n.7, p.1155-1163, Amsterdam, 2008.

[11] L.S. Lopes. Caracterização molecular da Linhagem Pedra 2 de Saccharomycescerevisae sob condições de alto etanol em fermentadores industriais. (Tese de mestrado). Universidade de São Paulo, Escola Superior de Agricultura "Luiz de Queiroz", Piracicaba, 2015.

[12] M.G.S. Andrietta, P.R. Kitaka, S.R. Andrietta, C. Steckelberg. Dominance and Persistence of PE strains (Saccharomyces sensustricto) in Brazilian bioetanol fermentation tanks (three units, one season). International Journal of New Technology and Research (IJNTR), v.3, I.7, p.22-25, 2017 